\title{
The Influence of Change Load Against Fuel Cost in Coal-fired Power Tarahan Lampung Unit 3 and 4
}

\author{
Endah Komalasari ${ }^{1}$, Rahmattulloh ${ }^{1}$, Herri Gusmedi ${ }^{1}$
}

\begin{abstract}
The operation of a power plant depends on fuel where fuel costs are incurred on a generating unit is a function of the plant load. The ability power plant carry the load determine the reliability of an electrical system, hence the power raised always be done equal to needs in side load all the time. Fluctuations demand of electrical power in side load will cause fluctuations change fuel cost. In this paper, the correlation both commonly called input-output characteristics of the power plant needs to be determined. These characteristics declared total input tons of coal per hour is used and net electrical output where the output power is available to the electric utility. One way to achieve this goal is to match polynomial regression on the data using a second order polynomial. This model allows the study of the incremental fuel cost resulting from a change load in a coal-fired power plant.
\end{abstract}

Keywords-Coal-fired power, economic dispatch, incremental cost characteristics, input-output characteristics, second order polynomial regression.

\section{INTRODUCTION}

$\mathbf{T}$ HE efficient and optimum economic operation and planning of electric power generation systems have always occupied an important position in the power industry. The efficient use of the available fuel is growing in importance, both in the monetary and because a large proportion of fuel is a source of natural resources being irreplaceable. An idea of the magnitude of the amounts of money under consideration can be obtained by considering the annual operating expenses of a large utility for purchasing fuel.

The original problem of economic dispatch for thermal systems was solved by numerous methods years ago. Recently there has been a rapid growth in method applied mathematics and the availability of computating ability to solve the problem of this nature that once broken problem. The classic problem is the economic dispatch of coal-fired power plants to achieve minimum operating cost. Many coal-fired power plant that operate efficiently but does not guarantee the minimum operations, because fuel cost that was too high. The cost of fuel in general are the biggest cost component, roughly 60 percent of the overall cost of the operation. [1,3-5]

In the operation of its required a method of reduce the cost of fuel considering different characteristics at a units of coalfires power plants in a systems. The coal-fired power plant need scheduling the operational pattern for generating plant, and it may be necessary for a utility to modify its economic schedule to facilitate the industrial generation pattern.

\footnotetext{
${ }^{1}$ Department of Electrical Engineering, Faculty of Engineering, Lampung University, Bandar Lampung 35145.

${ }^{*}$ Correspondence to Endah Komalasari, email: endah.komalasari@eng.unila.ac.id. Tel.:+62-721-704947; fax.:+62-721704948 .
}

This paper evalutes the input-output characteristics of a coal-fired power plant. The input-output characteristic was calculated in a $100 \mathrm{MW}$ coal-fired power plant unit 3 and 4 using polynomial regression. The input-output characteristic differences between both unit are discaussed. From these results, the value of the incremental cost is estimated.

\section{Characteristic OF POWER Plant Units}

A fundamental problem economic their operation is to determine the characteristics of an input-output units of coalfired power plant. In defining the unit characteristics, the gross input versus net output will be discussed. That is, gross input to the plant represents the total input, whether measured in terms of tons of coal per hour. The net output of the plant is the electrical power output available to the electric utility system. In defining the characteristics of coal-fired units, the following terms will be used

\section{$H=$ heat input to the unit (Mbtu/h)}

$F=$ fuel cost times $H=$ operating costs $(\mathrm{Rp} / \mathrm{h})$

Figure 1 shows the input-output characteristic of a coal-fired unit in idealized form. The input to the unit shown on the ordinate may be in term of heat energy requirements (million of Btu per hour or MBtu/h). The output is normally the net electrical output of the unit. The characteristic shown is idealized in that it is presented as a smooth and convex curve.

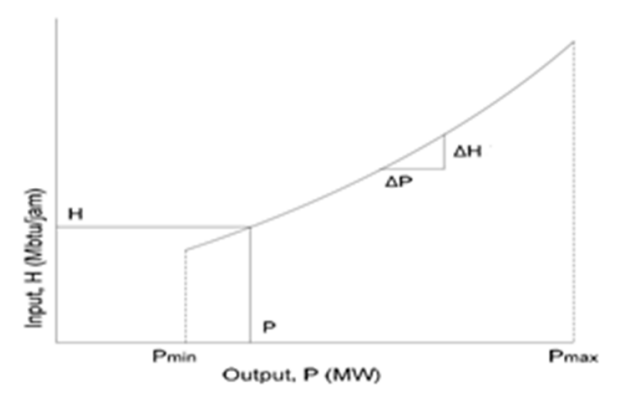

Fig 1. Input-output curve of a coal-fired power plant

The incremental heat rate or cost characteristic for a unit of this type is shown in Figure 2. The inremental cost characteristic is the slope or the derivative of the input-output characteristic. The data shown on this curve are in terms of Btu per kilowatt hour versus the net power output of the unit in megawatts. 
This characteristic is widely used in economic dispatching of the unit. It is converted to an incremental fuel cost characteristic by multiplying the incremental heat rate in Btu per kilowatt hour by the equivalent fuel cost in term of fuel cost times Btu per hour heat input. Frequently this characteristic is approximated by a sequence of straight-line segments.

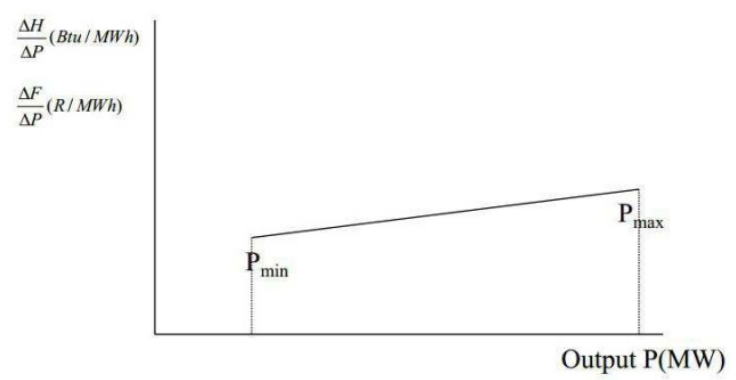

Fig 2. Incremental cost characteristic

\section{A. Subsection Heading Here}

Subsection text here.

1) Subsubsection Heading Here: Subsubsection text here.

\section{ANALYSIS METHODS}

The input-output characteristics can be searched using a second order polynomial regression method as follows: [6-8]

$$
H(\mathrm{Pi})=\mathrm{a}+\mathrm{b} \mathrm{Pi}+\mathrm{c} \mathrm{Pi}^{2}
$$

where $H(\mathrm{Pi})$ denotes the heat input to the unit $(\mathrm{Mbtu} / \mathrm{h}), \mathrm{a}, \mathrm{b}, \mathrm{c}$ are coefficien, and $\mathrm{Pi}$ is a output unit. Therefore, polynomial model for the generating units can be achieved through

$$
\begin{aligned}
& \sum H_{i}=a N+b \sum P+c \sum P^{2} \\
& \sum H_{i} P=a \sum P+b \sum P^{2}+c \sum P^{3} \\
& \sum H_{i} P^{2}=a \sum P^{2}+b \sum P^{3}+c \sum P^{4}
\end{aligned}
$$

Then the equation (2-4) can be solved through the invers matrix technique as follow :

$$
\left[\begin{array}{l}
a \\
b \\
c
\end{array}\right]=\left[\begin{array}{ccc}
N & \sum P & \sum P^{2} \\
\sum P & \sum P^{2} & \sum P^{3} \\
\sum P^{2} & \sum P^{3} & \sum P^{4}
\end{array}\right]^{-1}\left[\begin{array}{c}
\sum H_{i} \\
\sum H_{i} P \\
\sum H_{i} P^{2}
\end{array}\right]
$$

After solving input-output characteristic, the incremental cost characteristics is obtained from

$$
\begin{aligned}
& \Delta F / \Delta P=(\mathrm{b}+2 \mathrm{c} \mathrm{Pi}) \times \text { fuel cost } \\
& \Delta F / \Delta P=\lambda
\end{aligned}
$$

where $\Delta F / \Delta P$ is the slope of the input-output characteristic ( Rp/MWh), and $\lambda$ is the incremental cost.

\section{RESULTS AND DISCUSSION}

One of the main issues of concern around the world today is the energy crisis. Production of oil needed to generate electrical energy is not sufficient to meet the demands of consumers. In this condition, the power system must be efficient in the Economic Load Dispatch that minimizes the overall cost of generation. In 2013, Bommirani.B, et all[2] have been studying the optimization problem to minimize the total cost of supplying the load demand. She proposed a new approach to the solution of artificial bee colony $(\mathrm{ABC})$ algorithm and applied to six units system for simulate the maximize power output and minimize the fuel cost. The six unit generating units considered are having different characteristic. Their cost function characteristics are given by the equations obtained through the Matlab simulation. While in this paper, is to obtain a mathematical model to minimize the total cost of fuel needed to generate electricity in power plants within a specified time interval.

In this paper, the equation of cost function characteristics which will be determined based on the real problem Tarahan coal power unit 3 and 4, each with a capacity of $100 \mathrm{MW}$. The total load in a plant is supplied by two units. Fuel consumption in each generator unit depending on the load requirements of the generating unit itself. Table 1 and 2 is fuel consumption data coal and the power raised on power station unit 3 and 4 .

According to the table, the total load of unit 4 is higher than that of the other unit due to the requirement that the load of these generating units interconnected to larger. The heat is calculated by assuming the calorie fuel by $5000 \mathrm{Kcal} / \mathrm{kg}$.

Table 1. Fuel Consumption Data Unit 3

\begin{tabular}{lclc}
\hline \hline Month & $\begin{array}{c}\text { Fuel } \\
\text { Consumption } \\
(\mathbf{K g})\end{array}$ & $\begin{array}{c}\boldsymbol{H}(\mathbf{P i}) \\
(\mathbf{M b t u} / \mathbf{h})\end{array}$ & $\begin{array}{c}\text { Power } \\
(\mathbf{M W})\end{array}$ \\
\hline January & 25438388 & 678,41 & 76,57 \\
February & 27706350 & 738,89 & 87,75 \\
March & 29101300 & 776,09 & 92,87 \\
April & 26048800 & 694,69 & 75,71 \\
May & 28943300 & 771,88 & 87,84 \\
June & 32977300 & 908,78 & 97,85 \\
July & 25599179 & 705,45 & 76,87 \\
August & 28795200 & 793,53 & 86,91 \\
September & 31525938 & 840,75 & 91,40 \\
\hline \hline
\end{tabular}

Table 2. Fuel Consumption Data Unit 4

\begin{tabular}{lccc} 
& \multicolumn{3}{c}{ Table 2. Fuel Consumption Data Unit 4 } \\
\hline \hline Month & $\begin{array}{c}\text { Fuel } \\
\text { Consumption } \\
(\mathbf{K g})\end{array}$ & $\begin{array}{c}\boldsymbol{H}(\mathbf{P i}) \\
(\mathbf{M b t u} / \mathbf{h})\end{array}$ & $\begin{array}{c}\text { Power } \\
(\mathbf{M W})\end{array}$ \\
\hline January & 25819722 & 688,58 & 77,91 \\
February & 27416902 & 731,17 & 87,50 \\
March & 28548038 & 761,34 & 93,74 \\
April & 27273905 & 727,36 & 80,61 \\
May & 29964043 & 799,10 & 91,55 \\
June & 32070657 & 855,28 & 96,07 \\
July & 27501915 & 733,44 & 80,97 \\
August & 29575670 & 788,74 & 90,39 \\
September & 30541622 & 841,65 & 94,71 \\
\hline \hline
\end{tabular}

These data used to calculate values of the function an inputoutput. In these data, demonstrated a significant degree of error. The strategy to determine a single curve representing the general trend of the data. One approach using these properties is a polynomial regression. Then a simpler function that can be obtained to match these values.

By using a second order polynomial regression to match the data, obtained function of input-output as follows

Table 3. Input-output functions on generating units 3 and 4

\begin{tabular}{cc}
\hline \hline Power Plant & Function of input-output $(\mathbf{H}(\mathbf{P i}))$ \\
\hline Unit 3 & $2142,50-41,14 \mathrm{P}_{\mathrm{i}}+0,29 \mathrm{P}_{\mathrm{i}}{ }^{2}$ \\
Unit 4 & $2681,40-51,79 \mathrm{P}_{\mathrm{i}}+0,34 \mathrm{P}_{\mathrm{i}}{ }^{2}$ \\
\hline \hline
\end{tabular}

These function show the characteristics of coal-fired power plant units 3 and 4. Standard error of the estimate is based on regression polynomial function is 21,6. Determinant coefficient is 0,99913 and the correlation coefficient is 0,99957. These results support the conclusion that the least 
squares equation shows eminent suitability.

Figure 3 and 4 is a curve an input-output coal-fired power plant unit 3 and unit 4 Tarahan Lampung in JanuarySeptember 2015. Input of power plant shown in the vertical axis of heat energy required in the form of MBtu / h. The horizontal axis is the net electrical output of the unit power plant. The characteristic shown is a smooth and convex curve.

Every generating units in a plant have different input-output characteristics. The minimum and maximum output power generated at unit 3 respectively is $75.71 \mathrm{MW}$ and $97.85 \mathrm{MW}$. When output $75,71 \mathrm{MW}$, energy needs the heat generated by the namely 694,69 MBtu / h but during output 97,85 MW energy needs the heat of $908,78 \mathrm{MBtu} / \mathrm{h}$. In units of 4, output minimum produced $77,91 \mathrm{MW}$. With a capacity of this size, heat energy requirement $688,58 \mathrm{MBtu} / \mathrm{h}$. As for the maximum output is $96.07 \mathrm{MW}$, needs heat energy generated at 855.28 MBtu / h. As the unit loading increases, the input to the unit increases.

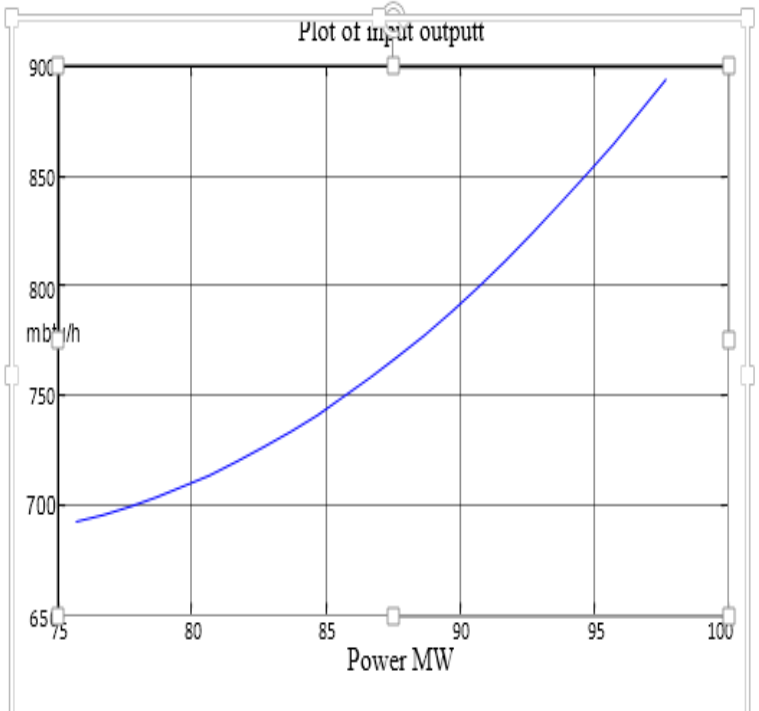

Fig 3. Input-output characteristics of unit 3

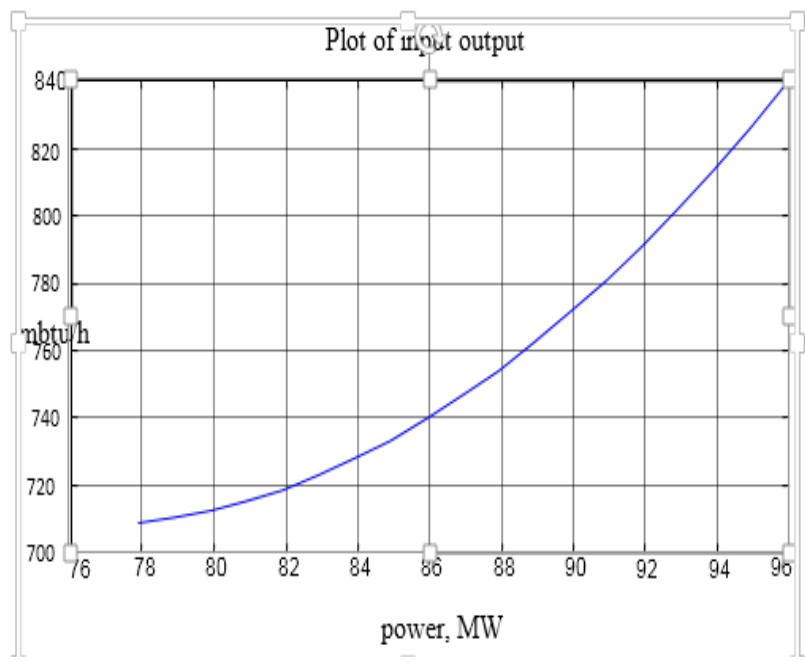

Fig 4. Input-output characteristics of unit 4

Based on a picture above, unit 4 have energy needs heat which is greater than the unit 3 . It was because fuel consumption unit 4 more in an appeal unit 3 to serve a bigger load.

If the heat energy is determined multiplied by the price of fuel, it can be stated as well as the total cost per hour ( $\mathrm{Rp} / \mathrm{h})$.
For this case, the cost of coal is Rp 691.000 per ton and conversion $1 \mathrm{MBtu}$ to ton is 0,0833 . By using the data in Table 3 , equation (6) and (7) is applied, the incremental cost of the unit 3 and unit 4 can be obtained as shown in Table 5 below.

Table 4. The derivative of input-output characteristic

\begin{tabular}{cc}
\hline \hline Coal-fired Power & $\Delta \mathbf{H} / \Delta \mathbf{P}(\mathbf{M B t u} / \mathbf{M W h})$ \\
\hline Unit 3 & $-41,14+0,58 \mathrm{Pi}$ \\
Unit 4 & $-51,79+0,68 \mathrm{Pi}$ \\
\hline
\end{tabular}

Table 5. Incremental cost of unit 3 and 4

\begin{tabular}{ccc}
\hline Load (MW) & \multicolumn{2}{c}{$\begin{array}{c}\text { Incremental Cost }(\lambda) \\
\text { (Rp 103/MWh) }\end{array}$} \\
\cline { 2 - 3 } 77 & Unit 3 & Unit 4 \\
80 & 202,61 & 32,81 \\
83 & 302,77 & 150,23 \\
86 & 402,92 & 267,65 \\
89 & 503,08 & 385,08 \\
92 & 603,23 & 502,50 \\
95 & 703,38 & 619,92 \\
98 & 803,54 & 737,34 \\
\hline
\end{tabular}

The incremental cost characteristic for unit 3 and 4 are shown in Figure 5 and 6. While the output of power plan shown in the horizontal axis that is the raised by coal-fired power plant Tarahan. This figure shows that incremental cost is quite linear with respect to power output over an appreciable range. The curve approximated by one straight lines.

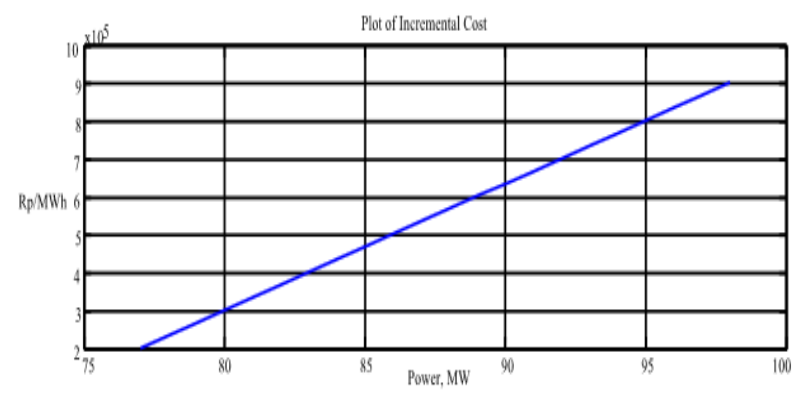

Fig 5. Incremental cost characteristics of unit 3

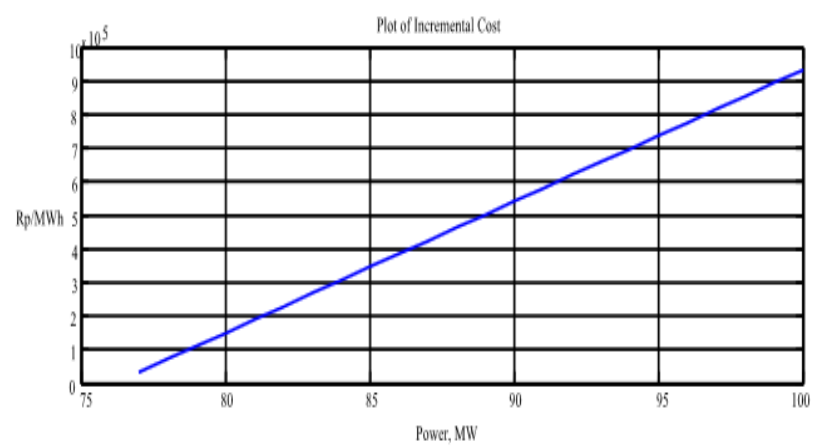

Fig 6. Incremental cost characteristics of unit 4

Incremental cost shows how the cost of fuel if raised in a 1 MW per hour. Two units have different incremental cost, then in order to decrease the total cost of generation, decrease the output power in unit having higher incremental cost and 
increase the output power in having lower incremental cost. Therefore, unit 4 kept working to serve the needs of a greater load than unit 3 as shown in the picture. When this process is continued, a stage will reach wherein incremental costs of all the units will be equal. Therefore the total cost of generation will be minimum.

Some of the load is transferred from the unit with higher incremental cost to the unit with lower incremental cost. Reducing the load on the unit with a higher incremental cost will result in greater reduction of cost than the increase in cost for adding the same amount of load to the unit with a lower incremental cost. The transfer of load from one to other can be continued with a reduction of total cost until the incremental costs of the two units are equal. In other words, unit 4 to supply a greater load with increasing costs less than 3 units.

\section{CONCLUSION}

In the present research, polynomial regression solution schemes for calculating input-output characteristic in generating units are proposed. The different results are obtained for every unit. However, the choice of solvers for the incremental cost characteristic affects results. A second order polynomial seems a good option especially to solve a larger problem of real symmetric linear equations. This method shows eminent suitability because the method keeps the level of the maximum the correlation coefficient. The unit 4 have needs greater heat energy from the unit 3 because the fuel consumption at unit 4 is greater than unit 3 to serve a larger load. Incremental costs on unit 4 is much smaller than the unit 3 because the unit keeps the level of the minimum the output power.

\section{REFERENCES}

[1] A.J. Wood, Power Generation, Operation, and Control, John Wiley \& Sons, Inc., 1996.

[2] Bommirani, B, Thenmalar.K "Optimization Technique for the Economic Dispatch in Power System Operation", Proceedings of National conference on Advances in Electrical Energy Applications, pp.1-5,2013.

[3] El-Hawary, Optimal Economic Operation of Electric Power Systems, Academic, New York, 1979.

[4] El-Wakil, M.M., Power Plant Technology, McGraw-Hill, 1984.

[5] Stoll, H.G., Least-Cost Electric Utility Planning, Wiley, New York, 1989.

[6] Steven C. Chapra, Numerical Methods for Engineering, Mc-Graw Hill, 1988.

[7] Tarek Bouktir, Linda Slimani, M. Belkacemi "A Genetic Algorithm for Solving the Optimal Power Flow Problem" Leonardo Journal of Sciences, ISSN 1583-0233, Issue 4, pp.46, January-June, 2004.

[8] Termitope Adefarati et al, "Computational Solution to Economic Operation of Power Plants', Electrical and Electronic Engineering 2013, pp. $139-148$ 